\title{
Thermally Induced Isomerisation Kinetics of the 9c11t and 10t12c Conjugated Linoleic Acids in Triacylglycerols as Studied by FT-IR Spectrometry Aided by Gas Chromatography
}

\author{
Alfred A. Christy* \\ Department of Science, Faculty of Engineering and Science, University of Agder, Serviceboks 422, Kristiansand, Norway
}

\begin{abstract}
Isomerisation kinetics of the 9c11t and 10t12c Conjugated Linoleic Acids (CLA) in triaclglycerols at isothermal conditions $\left(250,280\right.$ and $\left.325^{\circ} \mathrm{C}\right)$ has been studied by infrared spectroscopy. Fifteen micro liter portions of the glycerides were placed in micro glass ampoules and sealed under nitrogen. Several glass tubes containing the same triacylglycerols were then subjected to thermal treatment. The glass tubes were removed at regular time intervals, cut open, and a part of the contents in each glass tube analysed by infrared spectroscopy using a single reflectance attenuated total internal reflectance crystal accessory. Then the rest of the products in each of the glass tubes were analysed by gas chromatography after derivatisation.

The gas chromatographic results show that the 9t11c and 10t12c CLA isomers undergo a quick [1,5] sigmatropic transformations and form $8 \mathrm{c} 10 \mathrm{t}$ and $11 \mathrm{c} 13 \mathrm{t}$ respectively. These then form more stable $8 \mathrm{t} 10 \mathrm{t}, 9 \mathrm{t} 11 \mathrm{t}$ and 10t12t, 11t13t isomers respectively.

Formation of the other CLA isomers is in relatively small quantities for shorter thermal induction times. The chromatographic profiles also show that the thermal induction reaction can be considered as a reaction starting from the pair of isomers formed through the [1.5] sigmatropic rearrangements.

The intensity of one of the characteristic absorptions at $944 \mathrm{~cm}^{-1}$ arising from the out-of-plane $=\mathrm{C}-\mathrm{H}$ deformation in the CLAs was used as the quantitative measure of the remaining triaclglycerol in the heated samples. The activation energies determined for the isomerisation reactions are $25.50 \pm 0.30$ and $25.25 \pm 0.70 \mathrm{kcal} / \mathrm{mol}$ for the triacylglycerols containing $9 \mathrm{c} 11 \mathrm{t}(8 \mathrm{t} 10 \mathrm{c})$ and $10 \mathrm{t} 12 \mathrm{c}(11 \mathrm{c} 13 \mathrm{t})$ fatty acid isomers respectively.
\end{abstract}

Keywords: Conjugated Linoleic Acids, infrared spectroscopy, isomerisation, reaction kinetics, activation energy.

\section{INTRODUCTION}

Conjugated Linoleic Acids (CLA) are natural components found in animal products, such as meat and dairy products derived from ruminant animals. Conjugated Linoleic Acids have gained considerable attention in recent times because of their health benefits [1-4]. This interest followed by an explosion of research reports on the benefits of CLAs in the areas of cancer, heart disease, diabetes and many other areas [5-9]. The results in these reports are based on the studies on animals and the beneficial effects on humans are yet to be proven.

The conjugated isomers in milk and fats are generally found in trans/cis, cis/trans and trans/trans forms. There are several conjugated linoleic acids present in milk and fat from the cud-chewing animals. Out of these $9 \mathrm{c} 11 \mathrm{t}$ and $7 \mathrm{t} 9 \mathrm{c}$ are dominant with 9c11t comprising about $80-90 \%$ of all the conjugated linoleic acids. The isomer $9 \mathrm{c} 11 \mathrm{t}$ is also thought to be the most biologically active $[1,2]$. These isomers can also be found in hydrogenated vegetable oils [10]. The isomers

*Address correspondence to this author at the Department of Science, Faculty of Engineering and Science, University of Agder, Serviceboks 422, Kristiansand, Norway; Tel: +47-38141502; Fax: +47-38141071;

E-mails: alfred.christy@uia.no, christyalfred@hotmail.com
$9 \mathrm{c} 11 \mathrm{t}$ and $10 \mathrm{t} 12 \mathrm{c}$ formed in almost equal proportion in the alkali isomerised methyl linoleate [11]. The concentrations of the other isomers are negligible [11].

There are several reports in the literature regarding synthesis and mechanistic aspects of CLAs. Destaillats and Angers [12] prepared 8t10c and 11c13t CLA isomers by heat treatment of $9 \mathrm{c} 11 \mathrm{t}$ and $10 \mathrm{t} 12 \mathrm{c}$ CLAs. They demonstrated in one of their reports that most of the CLA isomers could be produced from a mixture of 9c11t and 10t12 CLA methyl esters [13]. The chemistry and mechanistic pathways involved in the formation of CLAs were also discussed in the above research reports. Christy [14] has also contributed to supplement the mechanistic aspects by demonstrating that CLA isomers could be produced by thermal induction of 9t12t LA. In a recent report Christy [15] demonstrated that the $[1,5]$ sigmatropic transformations and positional isomerisation could be achieved by subjecting triacylglycerols of CLAs to a suitable high temperature. All these reports paved the way for the formulation of a sequential series of CLA isomers illustrating the type of CLA isomers expected to form when thermally treating a particular CLA $[13,15]$. It is now clear that the formation of CLAs follows a series of [1, 5] sigmatropic transformation and positional isomerisation during thermal induction. The report clearly shows that the CLAs expected to form in the thermal induction of $9 \mathrm{c} 11 \mathrm{t}$ and 
$10 \mathrm{t} 12 \mathrm{c}$ can be represented by a partial series of the sequence (Fig. 1) presented in the report above. This sequence can be further shortened (Fig. 2) to represent the thermal induction of the respective isomers used in this study. This selection was based on the Gas chromatographic analysis of the thermally induced 9c11t (and 10t12c) containing triacylglycerols at $250^{\circ} \mathrm{C}$ for four hours (Fig. 3). When the induction time is shorter, the concentrations of the CLA isomers other than the isomers shown in Fig. (2) are small.

Infrared spectrometry, a valuable analytical tool has been applied both in qualitative and quantitative analysis [16]. It has also been applied to study chemical reactions and reaction kinetics [17]. In several cases, it has been the analytical tool of preference because of the specific absorptions of the species in the chemical reactions [18].

Conjugated linoleic acids 9c11t, 10t12c and all the other cis, trans and trans, cis CLAs give rise to two specific absorptions at 946 and $982 \mathrm{~cm}^{-1}$. These absorptions arise due to the $=\mathrm{CH}$ out of plane deformation vibration [19]. The $\mathrm{CH}$ out of plane deformation vibration of the $t$ (trans, trans) isomers absorb around $986 \mathrm{~cm}^{-1}$ and, cis. cis isomers do not absorb in this region. Furthermore, the $=\mathrm{CH}$ deformation vibrations of the methylene interrupted cis-trans, trans-cis and trans-trans linoleic acid isomers absorb around $969 \mathrm{~cm}^{-1}$
[20-23] which falls in between the two characteristic absorptions of the conjugated linoleic acids. This fact has been utilised in the simultaneous quantitative determination of isolated trans, and conjugated linoleic acids in oils and fats [24]. All the cis-trans and trans-cis isomers give rise to an absorption around $946 \mathrm{~cm}^{-1}$ that is not perturbed by other isomers.

There are no reports in the literature dealing with the thermally induced isomerisation kinetics of the $9 \mathrm{c} 11 \mathrm{t}$ and 10t12c CLAs in triacylglycerols. The intention in this work is to investigate the above mentioned isomerisation and determine the kinetic parameters using infrared spectroscopy. The fact that only mono trans conjugated linoleic acids absorb at $944 \mathrm{~cm}^{-1}$ would allow us to follow the concentration of CLA during the isomerisation. A single reflection ATR technique was used in measuring the infrared spectra of the samples. The infrared profiles of the CLAs during isomerisation were used in the determination of isomerisation rates as well as the activation energies.

\section{EXPERIMENTAL}

\section{Samples and Methods}

The triacylglycerols containing the $9 \mathrm{c} 11 \mathrm{t}$ and $10 \mathrm{t} 12 \mathrm{c}$ (over 94\%) and acid standards of the 9t11c and 9t11t fatty

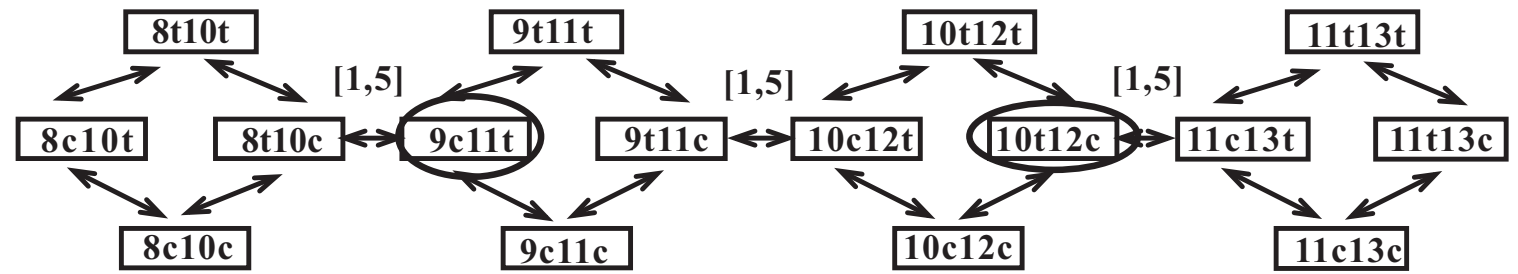

Fig. (1). Isomerisation sequence showing the isomers that are expected to form during thermal induction of triacylglycerols containing $9 \mathrm{c} 11 \mathrm{t}$ and $10 \mathrm{t} 12 \mathrm{c}$ CLAs.
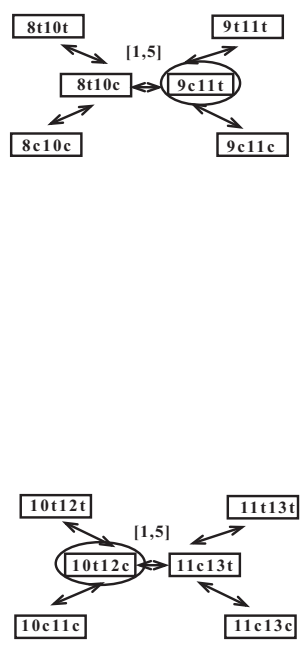
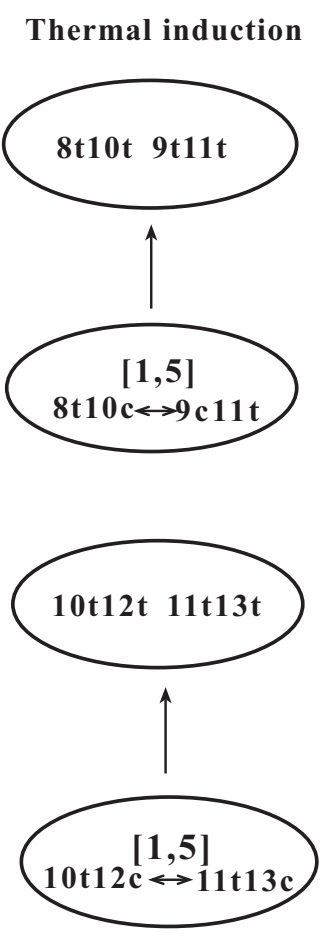

B

a) starting from $9 \mathrm{c} 11 \mathrm{t}$

A

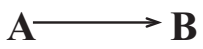

B

b) starting from $10 \mathrm{t} 12 \mathrm{c}$

A

Fig. (2). Sinplified sequence of isomerisation from the products formed after [1,5] sigmatropic transformation of 9c11t and 10t12c CLAs. 


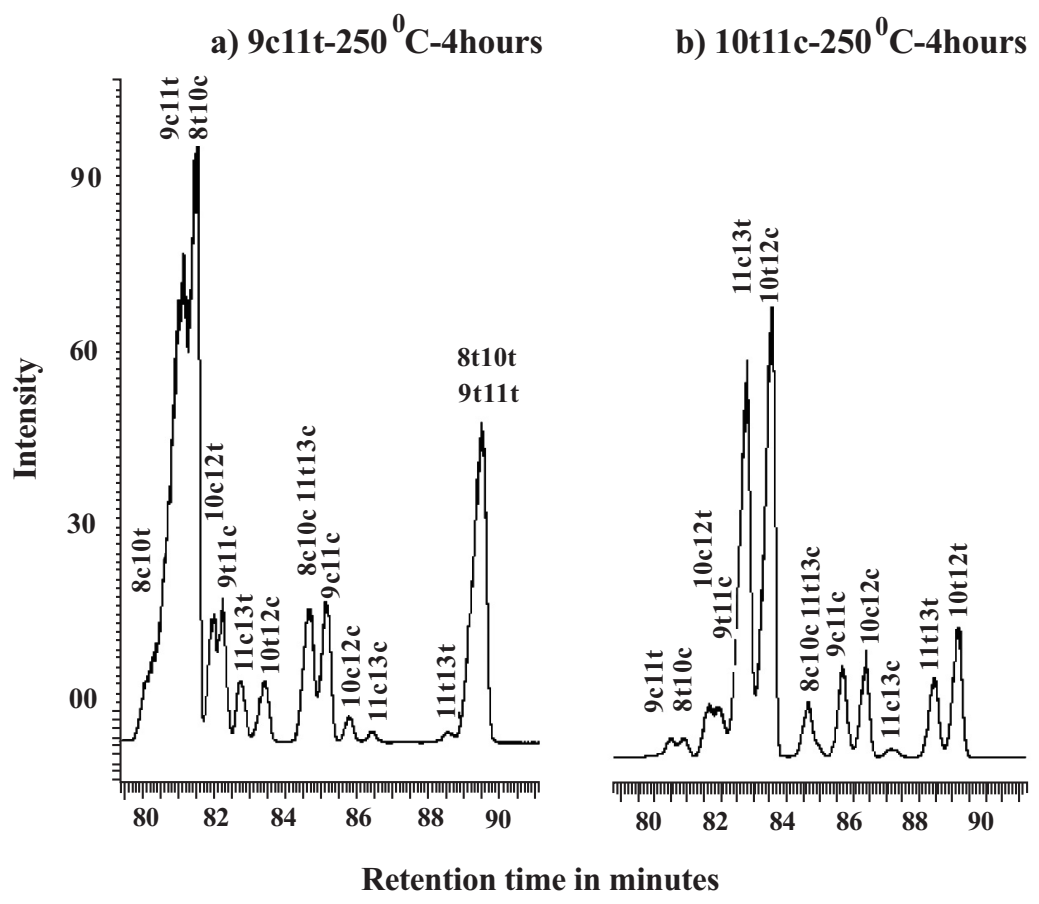

Fig. (3). Gaschromatograms of the products formed during the thermal induction of triacylglycerols containing $9 \mathrm{c} 11 \mathrm{t} / 10 \mathrm{t} 12 \mathrm{c}$ CLAs for four hours at $250^{\circ} \mathrm{C}$.

acids were purchased from Larodan Chemicals, Sweden. Triacylglycerol standards of the methyl interrupted $9 \mathrm{c} 12 \mathrm{c}$ and $9 \mathrm{t} 12 \mathrm{t}$ fatty acids were purchased from Aldrich.

The isomerisation kinetics of the two isomers was studied at 250,280 and $325{ }^{\circ} \mathrm{C}$. The heating experiments were carried out in micro glass ampoules. Several glass ampoules of length $4 \mathrm{~cm}$ were made from glass tubes of $1.5 \mathrm{~mm}$ internal diameter and a wall thickness of $1 \mathrm{~mm}$. Heating in micro size glass ampoules is an advantage experimentally [25]. The glass tubes attain the temperature of reaction within a short time and cools very fast when the tubes are removed from the oven. The experiments were started with the thermal treatment of the triacylglycerol containing the 9c11t isomer. $15 \mu \mathrm{l}$ portions of the triacylglyceerols were injected in the tubes using a plastic syringe. Air in the remaining part of the glass tubes was flushed by a weak flow of nitrogen and the ends were sealed using an oxy-propane flame. The glass tubes were placed in a chromatographic oven set at $250^{\circ} \mathrm{C}$. The glass tubes were removed at regular time intervals and the infrared spectra of the cooled samples were measured.

\section{Infrared Spectroscopic Measurements}

A Perkin Elmer Spectrum One FT-IR spectrometer equipped with a Harrick single reflectance ATR accessory and lead glycine sulphate detector was used in measuring the infrared spectra. The accessory requires only a thin layer of sample on the crystal to acquire the infrared spectrum. Each glass ampoule was cut open and the sample was spread on the ATR crystal using the blunt side of a capillary glass tube. A background spectrum was scanned in the range of 4000$600 \mathrm{~cm}^{-1}$ before the application of a sample. A total of 30 scans at a resolution of $4 \mathrm{~cm}^{-1}$ were then measured on each sample. The samples were measured immediately after their removal from the oven. The ATR crystal was washed with dichloromethane and acetone after each measurement. The same procedure was repeated at 280 and $325^{\circ} \mathrm{C}$ for the $9 \mathrm{c} 11 \mathrm{t}$ isomer and at the same three temperatures for the $10 \mathrm{t} 12 \mathrm{c}$ isomer.

\section{Gas Chromatographic Analysis}

The glass ampoules containing the rest of the triacylglycerol samples were subjected to derivatisation as described in Ref. 25. Each glass tube containing the sample was crushed inside a $15 \mathrm{~mL}$ test tube. The test tubes were then added $2 \mathrm{ml}$ of $0.5 \mathrm{M}$ sodium hydroxide in methanol and then placed in a water bath at $60{ }^{\circ} \mathrm{C}$ for $15 \mathrm{~min}$. After cooling, each test tube was added $2 \mathrm{~mL}$ of $\mathrm{BF}_{3} /$ methanol and placed in the water bath again for $10 \mathrm{~min}$. Each test tube was then added $2 \mathrm{~mL}$ of a saturated solution of $\mathrm{NaCl}$ and $1 \mathrm{~mL}$ heptane. The tubes were shaken and the methyl esters were extracted in heptane layers. The heptane layer was added anhydrous magnesium sulphate and the clear solution was stored in small brown vials for GC analysis. The GC analysis was carried out by using a Perkin Elmer, auto XL system gas chromatograph. A $100 \mathrm{~m}$ capillary column with $0.25 \mathrm{~mm}$ internal diameter coated with $0.20 \mu \mathrm{m}$ thick 90\%-bis-(cyanopropyl)-methyl polysiloxane stationary phase with small amount of phenyl groups in the backbone of the polymer (HP 88) was used in the separation of the methyl esters of the fatty acid isomers. A temperature program with initial temperature of $150^{\circ} \mathrm{C}$ with equilibration time of 1 minute, then a temperature gradient of $0.5{ }^{\circ} \mathrm{C} / \mathrm{min}$, up to $170^{\circ} \mathrm{C}$. The temperature was held at $170^{\circ} \mathrm{C}$ for 60 minutes. The carrier gas flow was set to 0.5 $\mathrm{ml} / \mathrm{min}$. The peak identification was carried out by comparing the reported conjugated linoleic acid profiles in the literature $[13,26-28]$ and methyl esters prepared from the 
triacylglycerols of the 9c11t and 10t12c CLAs, and CLAs $9 \mathrm{t} 11 \mathrm{c}$ and $9 \mathrm{t} 11 \mathrm{t}$ by using the same derivatisation method used above. The peaks in the chromatograms were then integrated and their relative percentages calculated.

\section{DATA HANDLING}

The spectra measured on the series were saved as absorption spectra. The spectra of the solid samples were normalised to the same height as the peak representing the $\mathrm{CH}$ stretching absorption at $2956 \mathrm{~cm}^{-1}$. The carbon chain in the triacylglycerol molecules remains the same during the isomerisation and a normalisation of spectra using this criterion is acceptable. Each infrared profile was then derivated twice and the depth of the valley representing the peak at $944 \mathrm{~cm}^{-1}$ was measured from the zero line. Mathematically, this depth will be proportional to the concentration of the unreacted CLAs in the sample. This depth is compared with that of the pure CLA to determine the fraction of CLA remaining in the mixture. The use of the second derivative in this case allows us to have a value that is purely of CLA isomer. Base line shift and overlapping of the peak at the base line area will not affect this value. A description of the second derivative technique and its applications in spectroscopy can be found elsewhere $[29,30]$.

\section{METHODOLOGY}

When a reaction of the type shown in Fig. (2) is in progress, the rate of the reaction can be give by the following general equation:

$\mathrm{d}[\mathrm{A}] / \mathrm{dt}=-\mathrm{k}[\mathrm{A}]^{\mathrm{n}}$

Where $\mathrm{A}$ is the starting material, $\mathrm{k}$ is the reaction rate for the reaction $\mathrm{A} \rightarrow \mathrm{B}$. and $\mathrm{n}$ is the order of the reaction with respect to $\mathrm{A}$.

The equation 1 can be written as follows and integrated for the concentration range and time interval as shown in equation 2 .
$\mathrm{d}[\mathrm{A}] /[\mathrm{A}]^{\mathrm{n}}=-\mathrm{kdt}$

$\left.[\mathrm{A}]^{(1-\mathrm{n})}\right]_{\text {Ao }}{ }^{\mathrm{At}} /(1-\mathrm{n})=-\mathrm{k}[\mathrm{t}]_{0}^{\mathrm{t}}$

Where $[\mathrm{A}]_{0},[\mathrm{~A}]_{\mathrm{t}}$ are concentrations of $\mathrm{A}$ at times 0 and $\mathrm{t}$ respectively.

The integral is valid for $n \geq 2$. When the order of the reaction is zero, the result becomes,

$[\mathrm{A}]_{0}-[\mathrm{A}]_{\mathrm{t}}=-\mathrm{kt}$

and for $\mathrm{n}=1$ the result becomes,

$\ln \left([\mathrm{A}]_{\mathrm{t}} /[\mathrm{A}]_{0}\right)=-\mathrm{kt}$

For a zero-order reaction, the concentration change is independent of the concentration of the reactant and it is only proportional to the time of the reaction. For a reaction of first order, the reaction rate is proportional to the concentration of the reactant in solution and $\ln ([\mathrm{A}] \mathrm{t} /[\mathrm{A}] 0)$ will be proportional to the time of the reaction. In this work the order of the reaction was determined by graphic correlations.

When the 9c11t (and 8t10c) fatty acid in the triacylglycerol isomerises to another isomer, the relationship between concentration of the unreacted fraction of the isomer and time can be investigated to determine the rate and order of the reaction. The activation energy needed to bring the molecules to an activated complex level during the isomerisation tells us nothing about the product/products formed. The product can be just one isomer or a mixture of several isomers. The end products formed and their amounts depend on the stabilities of the isomers formed. The heat induced isomerisation reactions can be presented in an energy level diagram as shown in Fig. (4). The isomers 9c11t and 8t11c are at the same energy level in the energy diagram. This is true because the carboxyl group and the glycerol back bone are far away from the conjugated double bonds. During heating these isomers form an intermediate state from which the products are formed.

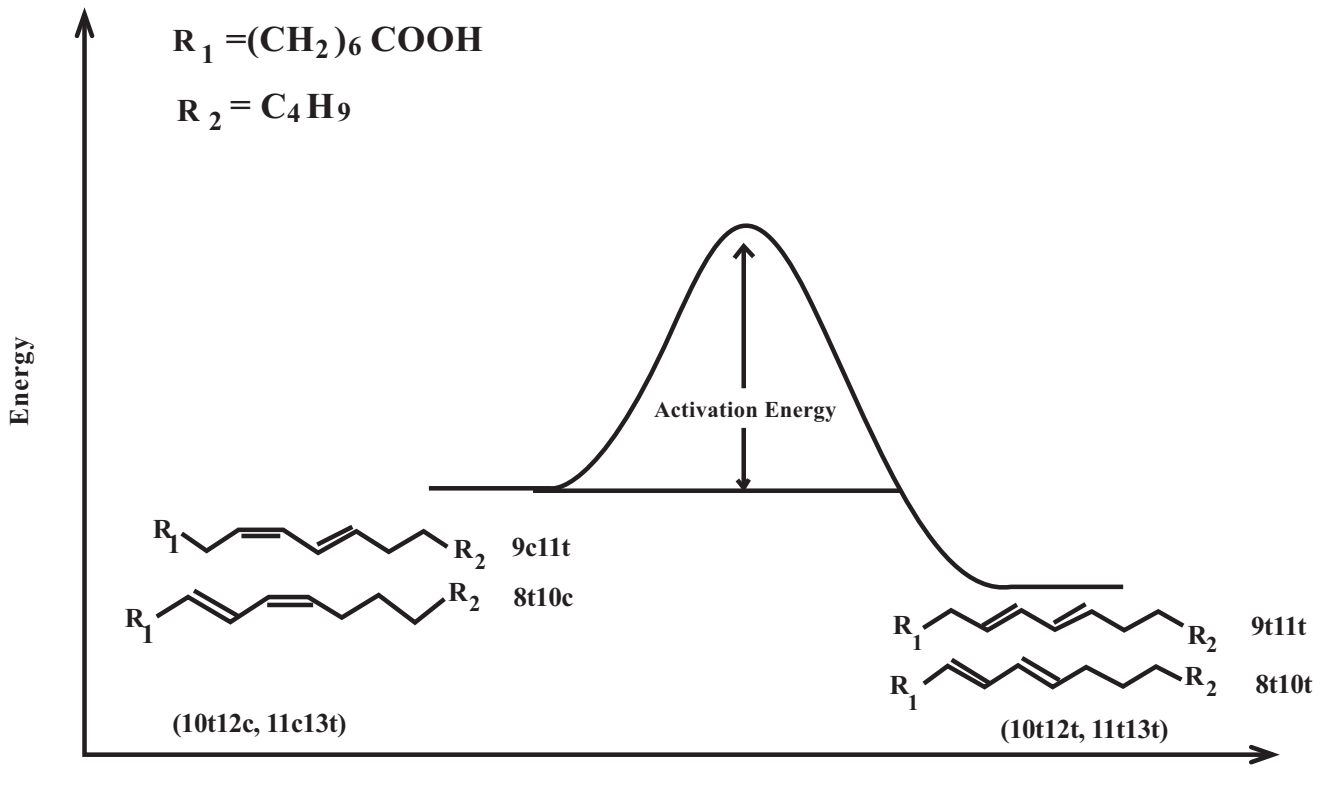

Reaction progress

Fig. (4). Energy diagram for the thermally induced isomerisation reaction. 
The activation energy for the isomerisation can be determined by carrying out the isomerisation at several different temperatures. The reaction rate and temperature of reaction are connected by the Arrhenius equation

$\mathrm{k}=A \exp \left(-\mathrm{E}_{\mathrm{a}} / \mathrm{RT}\right)$

$\ln \mathrm{k}=\ln A-\mathrm{E}_{\mathrm{a}} / \mathrm{RT}$

where, $A$ is Arrhenius constant, $\mathrm{R}$ is gas constant and $\mathrm{E}_{\mathrm{a}}$ is activation energy.

If the reaction rates of the isomerisation are determined for at least three different temperatures, the activation energy can be determined from the plot between $\ln \mathrm{k}$ and $1 / \mathrm{T}$.

\section{RESULTS AND DISCUSSION}

\section{Thermal Treatment of Triacylglycerols Containing 9c11t and 10t12c}

\section{Gas Chromatography}

The samples used in this work are triacylglycerols of the fatty acids $9 \mathrm{c} 11 \mathrm{t}$ and $10 \mathrm{t} 12 \mathrm{c}$. The CLA fatty acids referred in the following paragraphs represnt the triacylglycerols.

Thermally induced samples taken during regular time intervals were anslysed after derivatization as mentioned in the experimental section. The analysis of the isomers formed during the thermal induction of $9 \mathrm{c} 11 \mathrm{t}$ revealed that the concentrations of the isomers formed other than $9 \mathrm{c} 11 \mathrm{t}, 8 \mathrm{t} 10 \mathrm{c}$, $8 \mathrm{t} 10 \mathrm{t}$ and $9 \mathrm{t} 11 \mathrm{t}$ were small. Similarly, the thermal induction of $10 \mathrm{t} 12 \mathrm{c}$ revealed that the concentrations of the isomers formed other than $10 \mathrm{t} 12 \mathrm{c}, 11 \mathrm{c} 13 \mathrm{t}, 10 \mathrm{t} 12 \mathrm{t}$ and $11 \mathrm{t} 13 \mathrm{t}$ were small. Gas chromatograms of the fatty acid methyl esters of the isomers formed during the thermal induction of the $9 \mathrm{c} 11 \mathrm{t}$ and $10 \mathrm{t} 12 \mathrm{c}$ for four hours are given in Fig. (3). The concentrations of the other isomers increased with time during the thermal induction from the beginning of the thermal induction. However, the total concentration of these isomers reached around $4 \%$. Therefore, the concentration of these isomers was neglected in the kinetic analysis.

\section{Infrared Spectroscopy}

The infrared spectra measured from the samples taken at different time intervals during the isomerisation of $9 \mathrm{c} 11 \mathrm{t}$ (8t10c) and $10 \mathrm{t} 12 \mathrm{c}(11 \mathrm{c} 13 \mathrm{t})$ are shown in Figs. (5a and b) respectively. The figures clearly show that the peak at 944 $\mathrm{cm}^{-1}$ is reduced in intensity indicating the depletion of $9 \mathrm{c} 11 \mathrm{t}$ (8t10c) and $10 \mathrm{t} 12 \mathrm{c}(11 \mathrm{c} 13 \mathrm{t})$ isomers during the thermal induction. Only conjugated isomers of the $t c$ and $c t$ configurations absorb at this wave number. Therefore, the peak at 944 $\mathrm{cm}^{-1}$ in the infrared spectra of the heated samples represent the remaining $c, t$ and $t, c$ isomers in the mixture. The peak at $982 \mathrm{~cm}^{-1}$ behaves completely different from the peak at 944 $\mathrm{cm}^{-1}$. This behaviour indicates that there is a contribution from a peak representing a newly formed compound/s almost at the same wave number. This absorption arise from the formation of the $t, t$ CLA isomers.

The second derivatized spectral profiles of the infrared spectra of pure 9c11t isomer before the thermal treatment and after 4.5 hours thermal treatment are shown in Fig. (6). The depth measurement used in the kinetic studies in this paper to represent the concentration of the remaining reactant is indicated in the figure. It is possible to show by data subtraction that the products formed that give absorption at $986 \mathrm{~cm}^{-1}$ are $t, t$ isomers. The second derivative profile of the infrared spectrum of pure $9 \mathrm{c} 11 \mathrm{t}$ can be scaled so that the depth of the profile at $944 \mathrm{~cm}^{-1}$ is the same as the depth of the second derivative profile of a thermally treated $9 \mathrm{c} 11 \mathrm{t}$ (8c10t) (see Fig. 6). By subtracting the scaled profile of the pure $9 \mathrm{c} 11 \mathrm{t}$ sample from the profile of the products formed, a profile representing the second derivative of the products formed can be obtained. The result of the subtraction is shown in Fig. (7). The valley of the result is at $986 \mathrm{~cm}^{-1}$ where $=\mathrm{CH}$ deformation vibration of the $9 \mathrm{t} 11 \mathrm{t}(8 \mathrm{t} 10 \mathrm{c})$ isomer absorbs.

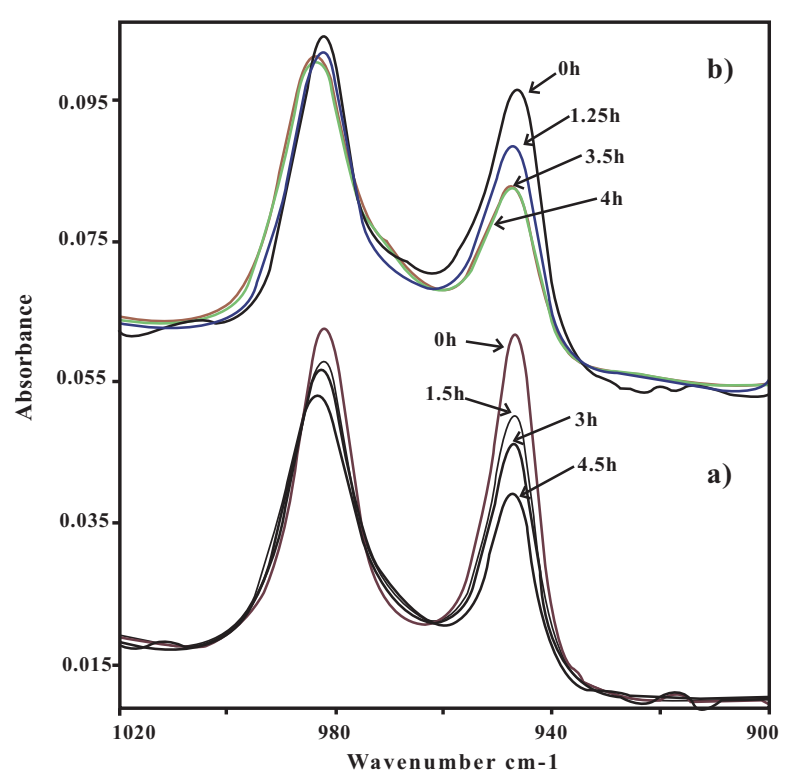

Fig. (5). Infrared spectra of the thermally induced CLA isomers. a) $9 \mathrm{c} 11 \mathrm{t}$ and b) $10 \mathrm{t} 12 \mathrm{c}$.

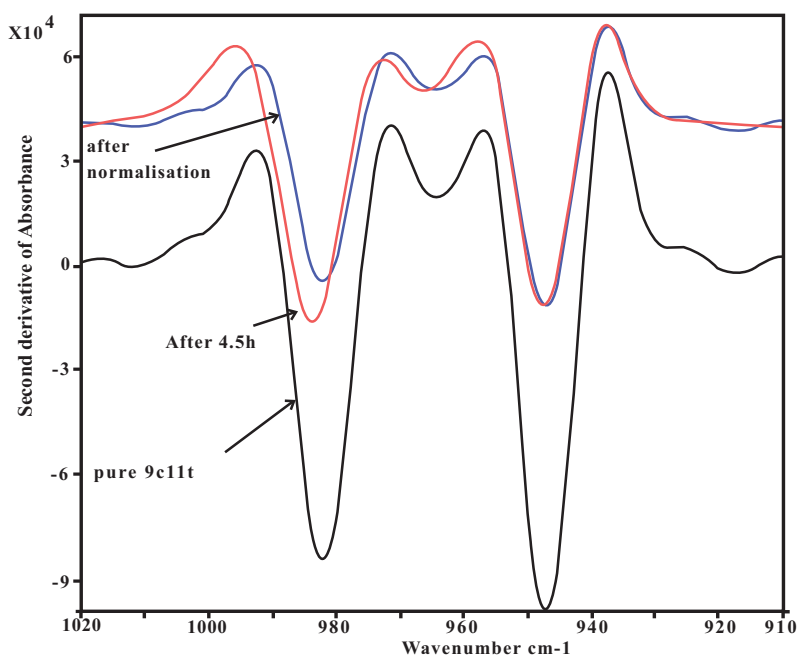

Fig. (6). Procedure used for normalisation of the peak at $944 \mathrm{~cm}^{-1}$ and subraction to reveal the product formed.

Applying the procedure mentioned above, the concentrations of the $9 \mathrm{t} 11 \mathrm{t}(+8 \mathrm{t} 10 \mathrm{t})$ isomers in the mixture during the 


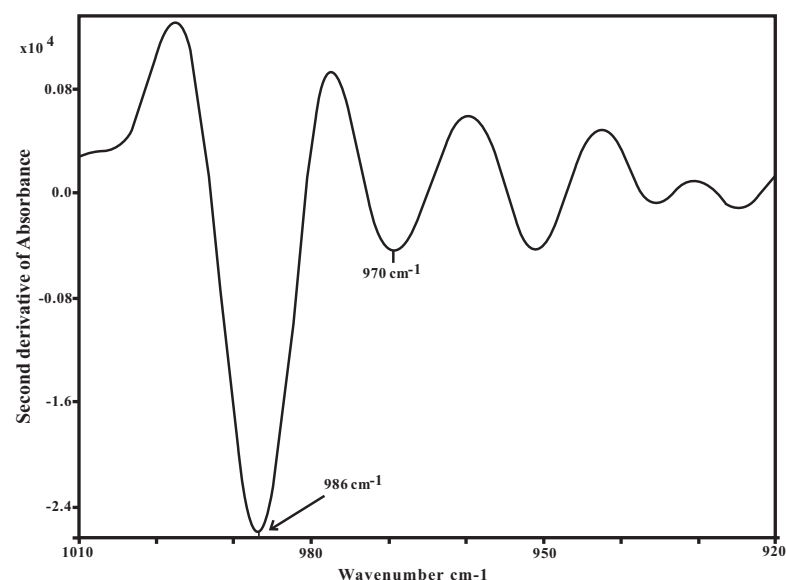

Fig. (7). The result of the subtraction (from Fig. 5).

reaction were estimated. The depletion rates of the $9 \mathrm{c} 11 \mathrm{t}$ $(+8 \mathrm{t} 10 \mathrm{t})$ and formation rate of the $9 \mathrm{t} 11 \mathrm{t}(+8 \mathrm{t} 10 \mathrm{t})$ are almost the same during the early part of the isomerisation and that the formation of methylene interrupted species are of little significance at these times/temperatures.

A prolonged thermal treatment of the isomers results into the complete depletion of the conjugated isomers and formation of products (Fig. 8) that give absorption at $970 \mathrm{~cm}^{-1}$. A recent report [15] shows that this peak is indeed from the absorption due to $9 \mathrm{t} 12 \mathrm{t}$ isomers (and very small concentrations of $9 \mathrm{c} 12 \mathrm{t}$ and $9 \mathrm{t} 12 \mathrm{c})$. The formation of $9 \mathrm{c} 11 \mathrm{t}$ and $10 \mathrm{t} 12 \mathrm{c}$ go through $9 \mathrm{t} 12 \mathrm{t}$ intermediate and the presence of $9 \mathrm{t} 12 \mathrm{t}$ in the thermally induced $9 \mathrm{c} 11 \mathrm{t}$ isomer is not unexpected.

Plots showing the correlations between $\ln \left([\mathrm{A}]_{\mathrm{t}} /[\mathrm{A}]_{0}\right)$ and reaction time are shown in Fig. (9) for the isomerisation reactions of $9 \mathrm{c} 11 \mathrm{t}(+8 \mathrm{t} 10 \mathrm{c})$ and $10 \mathrm{t} 12 \mathrm{c}(11 \mathrm{c} 13 \mathrm{t})$. Graphic plots showing the correlations between $\ln \mathrm{k}$ and $1 / \mathrm{T}$ are shown in Fig. (10). The linear correlations clearly indicate that the reactions are of 1 st order with respect to the CLA concentrtaions. The isomerisation rates and the weighted average activation energies determined using the plots shown in Fig. (8) are presented in Table 1. The values presented in the table suggest that these isomers have relatively the same activation energies of isomerisation.
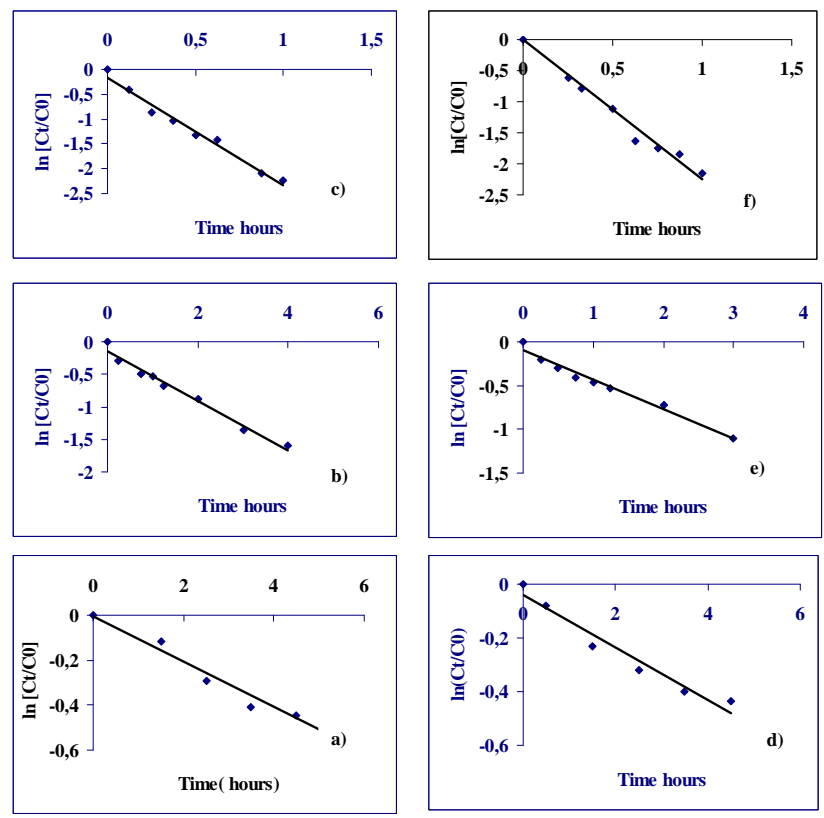

9c11t isome

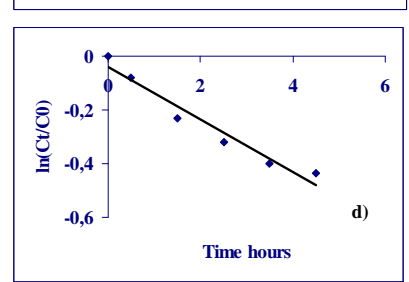

10t12c isomer

Fig. (9). Plots showing the correlations between $\ln [\mathrm{Ct} / \mathrm{C} 0]$ and time a), b) and c) are for the isomer 9c11t at temperatures 250, 280 and $325^{\circ} \mathrm{C}$ respectively. d), e) and f) are for the isomer $10 \mathrm{t} 12 \mathrm{c}$ at temperatures 250,280 and $325^{\circ} \mathrm{C}$ respectively.

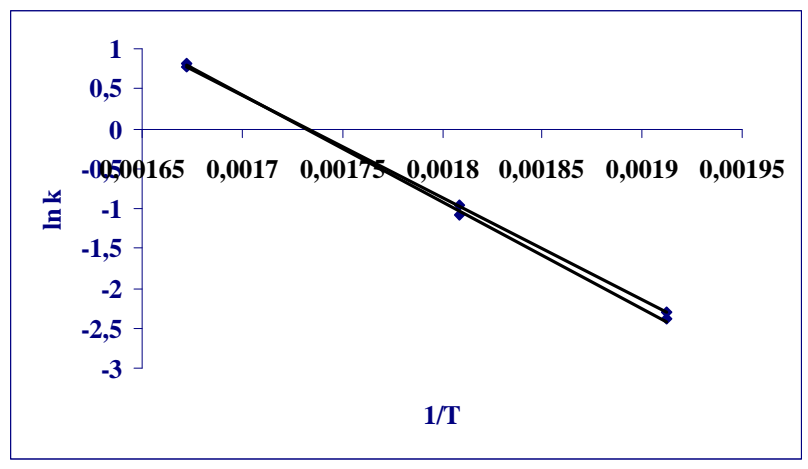

Fig. (10). The plots showing the relationships between $\ln \mathrm{k}$ and $1 / \mathrm{T}$.

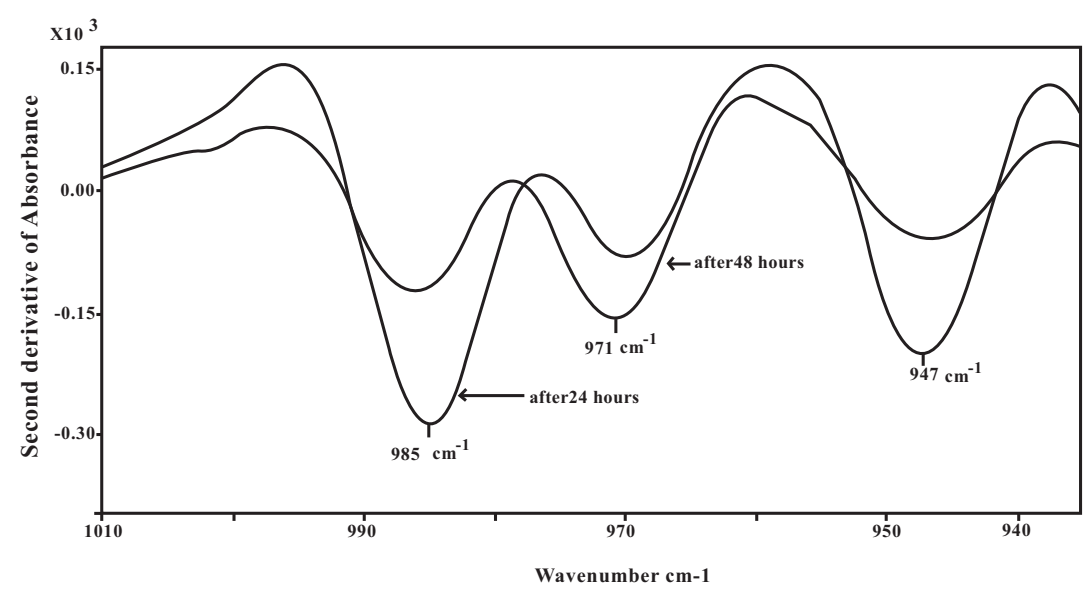

Fig. (8). The infrared spectra of the samples subjected to prolonged heat treatment, in the region of $1000-945 \mathrm{~cm}^{-1}$. 
Table 1. Kinetic Parameters for the Isomerisation

\begin{tabular}{|c|c|c|c|}
\hline Isomer & Temp Deg. C & k Reaction Rate 1/h & Activation Energy kcal/mol \\
\hline \hline 9c11t & 250 & $0.100 \pm 0.010$ & $25.50 \pm 0.30$ \\
\hline 9c11t & 280 & $0.380 \pm 0.023$ & $2.165 \pm 0.126$ \\
\hline 9c11t & 325 & $0.098 \pm 0.080$ & $25.25 \pm 0.60$ \\
\hline $\mathbf{1 0 t 1 2 c}$ & 250 & $0.335 \pm 0.025$ & \\
\hline $\mathbf{1 0 t 1 2 c}$ & 280 & $2.222 \pm 0.130$ & \\
\hline
\end{tabular}

\section{CONCLUSION}

In this paper, it has been demonstrated that infrared spectroscopy can effectively be applied in the determination of reaction rates and activation energies for the thermally induced isomerisations of the 9c11t (8t10c) and 10t12c (11c13t) isomers. These isomers follow a first order kinetics during the isomerisation. The activation energies determined for the isomerisation are in the same range as the activation energies for other chemical reactions in food systems [31].

The results from the isomerisation experiments have clearly proven that the isomers $9 \mathrm{c} 11 \mathrm{t}(8 \mathrm{c} 10 \mathrm{t})$ and $10 \mathrm{c} 12 \mathrm{t}$ (11c13t) disappear to form their trans-trans counterparts. The products are a mixture of almost all the CLA isomers with the predominence of the trans-trans isomers of the above.

A special experimental procedure was used with micro glass ampoules for the study of isomerisation kinetics. Only a fraction of a milli litre sample is required for the preparation of a series of samples. Similar procedure can be used in the study of reaction kinetics of high boiling organic compounds.

\section{REFERENCES}

[1] Ip C, Chin SF, Scimeca JA, Pariza MW. Mammary cancer prevention by conjugated dienoic derivatives of linoleic acid. Cancer Res 1991; 51: 6118-24.

[2] Ip C, Chin SF, Scimeca JA, Thompson HJ. Conjugated Linoleic acid. A powerful anticarcinogen from animal fat sources. Cancer Suppl 1994; 74: 1050-4.

[3] Nicolosi RJ, Courtemanche KV, Laitinen L, Scimeca JA, Huth PJ. Effect of feeding diets enriched in conjugated linoleic acid on lipoproteins and aortic atherogenesis in hamsters. Circulation 1993; 88: (suppl 2458).

[4] Shanta NC, Decker EA, Ustunol Z. Conjugated linoleic acids concentration in processed cheese, JAOCS 1992; 69: 425-8.

[5] Voorrips LE, Brants HA, Kardinaal AF, Hiddink GJ, Van den Brandt PA, Goldbohm RA. Intake of conjugated linoleic acid, fat and other fatty acids in relation to postmenopausal breast cancer: the Netherlands cohort study on diet and cancer. Am J Clin Nutr 2002; 76(4): 873-82.

[6] Belury MA, Vanden Heuvel JP. Protection against cancer and heart disease by the dietary fat, conjugated linoleic acid: potential mechanisms of action. Nutr Dis Update J 1997; 1: 58-63.

[7] Schrezenmeir J, Jagia A. Milk and diabetes. J Am Coll Nutr 2000; 19(90002): 176S-190.

[8] Scimeca JA, Miller GD. Potential health benefits of conjugated linoleic acid. J Am Coll Nutr 2000; 19(4): 470S-71.
[9] Parodi PW. Milk fat components-possible chemopreventive agents for cancer and other diseases. Aust J Dairy Technol 1996; 51: 2432.

[10] Cawood P, Wickens DG, Iversen SA, Braganza JM, Dormandy TL. The nature of diene conjugation in human serum, bile and duodenal juice. FEBS 1983; 162(2): 239-43.

[11] Berdeaux O, Voinot L, Angioni E, Juaneda P, Sebedio JL. A simple method of preparation of methyl trans -10 , cis-12 and cis-9, trans-11-Octadecadienoates from methyl linoleate. JAOCS 1998; 75(12): 1749-55.

[12] Destaillats F, Angers P. Evidence for [1, 5] sigmatropic rearrangements of CLA in heated oils. Lipids 2002; 30: 435-8.

[13] Destaillats F, Angers P. Directed sequential synthesis of conjugated linoleic acid isomers from $\Delta^{7,9}$ to $\Delta^{12,14}$. Eur J Lipid Sci Technol 2003; 105: 3-8.

[14] Christy AA. Evidence in the formation of conjugated linoleic acids from thermally induced 9t12t linoleic acid: A study by gas chromatography and infrared spectroscopy. Chem Phys Lipids 2009; 161: 86-94.

[15] Christy AA. Isomerization of $9 \mathrm{c} 11 \mathrm{t} / 10 \mathrm{t} 12 \mathrm{c}$ in triacylglycerols. Lipids 2010; 45: 733-41.

[16] McDonald RS. Infrared Spectrometry. Anal Chem 1984; 56(5): 349R-72R.

[17] Fishman AI, Stolov AA. Vibrational spectroscopic approaches to confirmational equilibria and kinetics (in condensed media). Spectrochim Acta 1993; 49A(10): 1435-79.

[18] Christy AA, Grung B, Kvalheim OM, Nyhus AK, Hagen S, Schanche JS. Friedel-craft acylation on porous divinyl benzene polymer particles-A reaction kinetic process studied by mid and near infrared spectroscopy. Appl Spectrosc 1998; 52: 1230-9.

[19] Mossoba MM, McDonald RE, Armstrong DJ, Page SW. Identification of Minor $\mathrm{C}_{18}$ triene and Conjugated Diene Isomers in Hydrogenated Soybean Oil and Margarine by GC-MI-FT-IR Spectroscopy. J Chromatogr Sci 1991: 29: 324-30.

[20] Mossoba MM, Yurawecz MP, McDonald RE. Rapid determination of total trans content of neat hydrogenated oils by attenuated total reflection spectroscopy. JAOCS 1996; 73(8): 1003-9.

[21] Belton PS, Wilson RH, Sadehgi-Jorabegi H, Peers KE. A Rapid Method for the Estimation of Isolated trans double bonds in Oils and fats Using FTIR combined with ATR. Lebensm Wiss Technol 1998; 21: 153-7.

[22] Dutten HJ. Analysis and Monitoring of Trans-isomerization by IR ATR Spectrometry. JAOCS 1974; 51: 406-9.

[23] Lancer AC, Emkem EA. Comparison of FTIR and capillary GC methods for quantitation of trans Unsaturation in fatty acids methyl esters. JAOCS 1988; 65: 1483-7.

[24] Christy AA, Egeberg PK, Østensen ET. Simultaneous Quantitative determination of isolated trans fatty acids and conjugated linoleic acids in oils and fats by chemometric analysis of the infrared profiles. Vib Spectrosc 2003; 33: 37-48.

[25] Christy AA, Xu Z, Harrington PB. Thermal degradation and isomerisation kinetics of triolein studied by infrared spectrometry and GC-MS combined with chemometrics. Chem Phys Lipids 2009; 158: 22-31.

[26] Yurawecz MP, Roach JAG, Sehat N, et al. A new conjugated linoleic acid isomer, 7trans, 9 cis octadecanoic acid, in cowmilk, 
cheese, beef and human milk and adipose tissue. Lipids 1998; 33 : 803-9.

[27] Berdeaux O, Voinot L, Angioni E, Juaneda P, Sebedio JL. A simple method of preparation of methyl trans -10, cis-12 and cis-9, trans-11-Octadecadienoates from methyl linoleate. JAOCS 1998; 75: 1749-55.

[28] Eulitz K, Yurawecz MP, Sehat N, et al. Preparation, separation, and confirmation of the eight geometrical cis/trans conjugated linoleic acid isomers 8,10-through 11, 13-18: 2. Lipids 1999; 34: 8737 .
[29] Christy AA. New insights into the surface functionalities and adsorption evolution of water molecules on silica gel surface: A study by second derivative near infrared Spectroscopy. Vib Spectrosc 2010; 54: 42-9.

[30] Owen AJ. Use of Derivative spectroscopy. Application Notes. Agilent Technologies 2001; Publication Number 5963-3940E.

[31] Villota R, Hawkes JG. Reaction kinetics in food systems. In: Heldman DR., Lund DB, Eds. Handbook of food engineering, New York: Marcel Dekker 1992; pp. 39-144.

(c) Alfred A. Christy; Licensee Bentham Open.

This is an open access article licensed under the terms of the Creative Commons Attribution Non-Commercial License (http://creativecommons.org/licenses/by-nc/3.0/) which permits unrestricted, non-commercial use, distribution and reproduction in any medium, provided the work is properly cited. 